\title{
Could the Baby Bonus be a bonus for babies?
}

\author{
Caroline M de Costa and Mark Wenitong
}

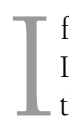
f we are ever to "close the gap" in life expectancy between Indigenous and non-Indigenous Australians, we must start in the womb. Perinatal mortality rates for the babies of Indigenous women are more than twice those of non-Indigenous babies. ${ }^{1}$ Rates of preterm birth for Indigenous women are double those of nonIndigenous women, and low birthweight, due to preterm birth, intrauterine growth restriction, or both, is two to three times more likely in Indigenous babies than in non-Indigenous babies. ${ }^{1,2}$

Low birthweight not only predisposes infants to greater risks of death and disease in the neonatal period, it can also portend serious chronic illness in later life. Fetal growth restriction is a risk factor for cardiovascular and respiratory disease, hypertension, type 2 diabetes, osteoporosis and affective disorders in adolescent or adult life. ${ }^{3}$ Many Indigenous babies start life already programmed for an early death from one or more of these conditions.

Higher rates of cigarette smoking, adolescent pregnancy and grand multiparity have been noted in Indigenous women. ${ }^{1,2}$ Fetal alcohol syndrome is reported much more commonly in the infants of Indigenous than non-Indigenous mothers, and is a lifelong disability with significant implications for the individual, the family and the society in which the affected child lives. ${ }^{4,5}$ Anaemia, undernutrition, renal disease, many types of infection, diabetes, rheumatic heart disease and hypertension are all common problems among Indigenous women. All these problems are linked directly or indirectly to social disadvantage over many generations, and all have the potential to increase the risks of pregnancy not only for women but also their children. ${ }^{6}$

Although around 98\% of Indigenous women give birth in hospital, they tend to present later in pregnancy than do nonIndigenous women and, hence, they have fewer antenatal visits. ${ }^{7,8}$

Antenatal care can never completely compensate for the impact of chronic disease or social disadvantage, nor can it guarantee a healthy normal child, but it does offer health professionals the chance to detect and offer treatment for certain conditions. ${ }^{9-11}$ Appropriate antenatal care is, in fact, the perfect model of primary care - primary care for the fetus, giving the best possible start to extrauterine life. Maternal anaemia, diabetes and hypertension can be detected and managed; urinary tract infections, sexually transmitted and other infections can be diagnosed and treated; risk factors for preterm birth can be identified and arrangements for appropriate birth settings made. Advice can be given about ceasing or decreasing cigarette and alcohol consumption and about healthy eating during pregnancy. There is some evidence to show that digital photos of the fetus in the first trimester from a simple twodimensional ultrasound scan can help mothers identify with their developing fetus and decrease alcohol and cigarette consumption. ${ }^{12}$

There are no national Australian guidelines for the timing and content of antenatal visits, but most non-Indigenous women present for antenatal care within the first trimester of pregnancy (and many attend general practitioners for prenatal checks to ensure the best possible health before attempting conception). Women in rural areas, women presenting to public hospital antenatal clinics, and Indigenous women are less likely to present for care in the first trimester than are women in urban areas and those with private health insurance. ${ }^{1,10}$ Yet it is the former groups

\section{ABSTRACT}

- Closing the gap in life expectancy between Indigenous and non-Indigenous Australians needs to start in the womb.

- Rates of perinatal mortality, preterm birth and low birthweight are two to three times greater among the babies of Indigenous women than among those of non-Indigenous women; low birthweight predisposes infants to greater risks of chronic illness in later life.

- Indigenous women in Australia tend to present for antenatal care later in pregnancy than do non-Indigenous women.

- There are many barriers for Indigenous women seeking to access antenatal care - geographical, social, cultural, financial and in some cases a lack of service provision. Many of these problems are being addressed within the public health system and by Indigenous community-controlled health services. However, more needs to be done.

- While antenatal care cannot solve all medical and social problems, commencing such care as early as possible in pregnancy has the potential to improve maternal health and hence pregnancy outcomes.

- Changes in the way the government Baby Bonus is paid to new mothers could act as an incentive not only to service providers but also to women themselves to initiate antenatal care in the first trimester of pregnancy. Such a system has been well established for many years in France.

- Any changes to the Baby Bonus scheme should provide incentives and not be punitive in nature.

MJA 2009; 190: 242-243

For editorial comment, see page 232

who are most likely to be socially disadvantaged, most likely to have complicated pregnancies and poorer outcomes, and most likely to benefit from earlier booking for antenatal care. Although antenatal care is important for all Australian women, it is vital that Indigenous women in particular, in both rural and urban areas, have improved access to good antenatal care if their health and that of their children is to improve.

Barriers to antenatal care for Indigenous women exist at many levels - socioeconomic constraints, educational and family factors, geographical distance from services, a lack of affordable transport, the infrequency (or absence) of local clinics, and the provision of culturally inappropriate services may all play a role. ${ }^{6,8}$ Many of these problems have been addressed by individual service providers within the mainstream public hospital sector, often through allowing a greater role for midwives and Indigenous health workers in antenatal clinics, and the provision of antenatal care through services controlled by Aboriginal communities. However, major inequalities in outcomes persist. Although further improvements to existing services and access to these services are clearly necessary, additional measures may also be appropriate.

Across Australia, the Baby Bonus has, until recently, been payable to all families after the birth of a child. This payment, in 
the words of the Australian Government's Family Assistance Office, "recognises the extra costs incurred at the time of a new birth or adoption of a baby". ${ }^{13}$ On 1 January 2009, changes were made to the Baby Bonus scheme. The payment is now restricted to families with a combined income of $\$ 75000$ or less in the 6 months following the birth of the child, and the lump sum has been replaced by 13 fortnightly instalments. ${ }^{14}$ In making these changes, the Australian Government recognised the need to try to make the payment a genuine health bonus for babies themselves - especially the babies of less well-off parents. To date, there have been no restrictions on how parents spend the bonus; the government has, we believe appropriately, assumed that parents are the best people to make such decisions for their children.

In France, generous maternity benefits have been available to new mothers for many years, but the system differs significantly from the current Australian model. ${ }^{15}$ Benefits are always paid in instalments, and the first instalment depends on the woman registering for antenatal care with an approved doctor or midwife by the 14th week of pregnancy. Women who register later than this are still paid maternity benefits but a lesser amount than that given to women who made an antenatal visit in the first trimester.

This system appears to work well in France: data show that about $96 \%$ of women giving birth in France are registered by 14 weeks of pregnancy, and among the remaining $4 \%$ are probably a number not eligible for French benefits. ${ }^{16}$ After the birth, mothers can receive further payments when the child is brought for routine medical checkups and for immunisations.

Other schemes in which direct financial incentives have been provided to improve health outcomes have had mixed results. For example, where a direct cash payment is connected to a health measure, such as giving up cigarette smoking, the results tend to be temporary. ${ }^{17}$ However, the French maternity benefits scheme does appear to be very successful in encouraging women to present early for antenatal care. ${ }^{16}$

In Australia, there are already some financial incentives for health care - the most obvious example is the benefit paid for childhood immunisations. Should we consider a similar scheme to encourage early presentation for antenatal care?

The idea of deducting some of the Baby Bonus from women who do not present early in pregnancy seems punitive - we need a carrot not a stick - but perhaps we could consider either a modest increase in the payment for women who present in the first trimester (for a full booking visit), or an earlier payment of the first instalment so that part of the bonus payment could be accessed by women booking in the first 3 months of pregnancy. A positive early engagement with the primary health care system would not only allow earlier detection of the health problems already mentioned but also give the opportunity to improve the woman's general health and to address risk factors, such as diet, from early pregnancy onwards. Early and positive contact might also help establish an effective ongoing collaboration between the woman and her antenatal care provider. Payment of the Baby Bonus from the first trimester may also assist women in remote areas with transport costs and allow them to access care.

Redefining how the Baby Bonus is paid would send a clear message both to service providers and to women themselves. For healthy women in good social circumstances antenatal care is important, but it is nevertheless something they are often able to manage well themselves. However, for women with poorer overall health, often in disadvantaged social circumstances (and not only
Indigenous women), early attendance for antenatal care has the potential to turn a moderate or poor pregnancy outcome into a healthier baby of greater birthweight with better prospects in life.

Starting with care in the womb means that by 2020 we could have a cohort of Indigenous children with realistic expectations of a longer, healthier life than we have today.

\section{Competing interests}

None identified.

\section{Author details}

Caroline M de Costa, FRANZCOG, FRCOG, MPH, Professor of Obstetrics and Gynaecology 1

Mark Wenitong, BMed, Senior Medical Officer ${ }^{2}$

1 James Cook University School of Medicine, Cairns, QLD.

2 Apunipima Cape York Health Council, Cairns, QLD.

Correspondence: caroline.decosta@jcu.edu.au

\section{References}

1 Rumbold AR, Cunningham JA. Review of the impact of antenatal care for Australian Indigenous women and attempts to strengthen these services. Matern Child Health J 2008; 12: 83-100.

2 Panaretto K, Lee $H$, Mitchell M, et al. Risk factors for preterm, low birth weight and small for gestational age birth in urban Aboriginal and Torres Strait Islander women in Townsville. Aust N Z J Public Health 2006; 30: 163-170.

3 Pike KC, Hanson MA, Godfrey KM. Developmental mismatch: consequences for later cardiorespiratory health. BJOG 2008; 115: 149-157.

4 Rothstein J, Heazlewood R, Fraser M. Health of Aboriginal and Torres Strait Islander children in remote Far North Queensland: findings of the Paediatric Outreach Service. Med J Aust 2007; 186: 519-521.

5 Coyne KL, de Costa CM, Heazlewood RJ, Newman HC. Pregnancy characteristics of women giving birth to children with fetal alcohol syndrome in Far North Queensland. Aust N Z J Obstet Gynaecol 2008; 48: 240-247.

6 Eades S. Maternal and child health care services: actions in the primary health care setting to improve the health of Aboriginal and Torres Strait Islander women of childbearing age, infants and young children. Canberra: Australian Government Department of Health and Ageing, 2004

7 de Costa CM, Child A. Pregnancy outcomes in urban Aboriginal women. Med J Aust 1996; 164: 523-526.

8 Panaretto KS, Lee HM, Mitchell MR, et al. Impact of a collaborative shared antenatal care program for urban Indigenous women: a prospective cohort study. Med J Aust 2005; 182: 514-519.

9 Powell J, Dugdale AE. Obstetric outcomes in an Aboriginal community: a comparison with the surrounding rural area. Aust J Rural Health 1999; 7: 1317

10 Nel P, Pashen D. Shared antenatal care for Indigenous patients in a rural and remote community. Aust Fam Physician 2003; 32: 127-131.

11 Carroli G, Villar J, Piaggio G, et al; WHO Antenatal Care Trial Research Group. WHO systematic review of randomised controlled trials of routine antenatal care. Lancet 2001; 357: 1565-1570.

12 Sedgmen B, McMahon C, Cairns D, et al. The impact of two-dimensional versus three-dimensional ultrasound exposure on maternal-fetal attachment and maternal health behavior in pregnancy. Ultrasound Obstet Gynecol 2006; 27: 245-251.

13 Australian Government Family Assistance Office. Baby Bonus. http:// www.familyassist.gov.au/internet/fao/fao1.nsf/content/payments-maternity payment (accessed Jan 2009).

14 Australian Government Family Assistance Office. Changes to the Baby Bonus from 1 January 2009. http://www.familyassist.gov.au/internet/fao/fao1.nsf/ content/payments-maternity_payment-baby_bonus_1jan2009.htm (accessed Jan 2009).

15 SOSbebe. Demarches: le remboursement des soins. http://www.sosbebe.org/guide/demarches/dem2.html (accessed Jan 2009).

16 Blondel B, Saurel-Cubizolles M-J. An indicator of adverse pregnancy outcome in France: not receiving maternity benefits. J Epidemiol Community Health 1991; 45: 211-215.

17 Gertler P. Do conditional cash transfers improve child health? Evidence from PROGRESA's control randomized experiment. Am Econ Rev 2004; 94: 336 341.

(Received 15 Jun 2008, accepted 7 Aug 2008) 